\title{
Early Pest Detection in Tomato Plantation using Image Processing
}

\author{
Prathibha G P, T G Goutham, Tejaswini M V, Rajas P R, Mrs Kamalam Balasubramani \\ Dept. of Information Science \& Engineering \\ Atria Institute of Technology \\ Bangalore- India
}

\begin{abstract}
Agriculture in India is aimed towards increase of productivity and food quality at reduced expenditure and with increased profit. The damages of crops caused by various diseases are increasing rapidly. In India, Tomato is one of the largely produced crops which come third in the production and is being used on a frequent basis by the people in their daily food consumption. Borer is the insect which affects the tomato in early stages. So, proper measures need to be taken at early stages to fight against them while minimizing the use of pesticides. The major challenge in agriculture field is early pest detection. In the proposed system, an attempt has been made to develop software for pest detection on the infected tomato. In our project, we capture the image of tomatoes and give it as an input. The input image goes through several stages to detect the number of borers, so that minimum amount of pesticides can be used.
\end{abstract}

\section{Keywords}

Early pest detection, image processing, feature extraction, tomato, borer

\section{INTRODUCTION}

Tomato is the third largest produced fruit in India which is being used on a frequent basis by the people in their daily food consumption. The damages caused by various diseases are increasing rapidly. Today there are plenty of pesticides being used in order to overcome these damages. The poisonous pesticides protect plant from insect attack and disease spread. When such fruits or vegetables are consumed by humans it may lead to health hazards in them and also there is a chance of such chemicals getting washed away by the rain and reach underground water, there by contaminating the earth's water reserve. For effective pest management, agricultural crops need an on-time detection of diseases. Manual methods are very time consuming, where it also depends on individuals' observing skills. Researches have been carried out to control these diseases by a biological means instead of using pesticides. Borers are insects that attack variety of plants including tomatoes. It enters into tomato plant stem or fruit by making a small entrance hole which is often difficult to locate. Such affected plants die and has to be uprooted and destroyed. A borer damaged plant that has been given a good care may survive. For this, the tomatoes affected by borer have to be detected at an early stage. This diagnosis is a tedious task to perform manually. Hence detection of biological objects which are very small is real challenge. With recent advancement in image processing, it is possible to develop a system to identify the initial pest affected tomatoes.

\section{EXISTING SYSTEM}

There are many researches going on about the early pest detection. One of the major papers on this is detection of whitefly. Whitefly is a bio-aggressor which poses a threat to a multitude of crops, was chosen as the pest of interest in many papers. A paper which was tested for several whiteflies affecting different leaves and an accuracy of $96 \%$ of whitefly detection was achieved [1].

According to a paper published in "Computers and Electronics in Agriculture 62, 2 (2008) 81-93" a strategy for identification of whitefly were applied to leaves of roses. [2]

In International Journal of Electrical, Electronics and Computer Engineering and IOSR Journal of Electronics and Communication Engineering (IOSR-JECE) a system for detection of pest had chosen Whiteflies as there object of interest because this pest requires early detection and treatment to prevent durable infection. Samples are collected by using the pan tilt camera with zoom in greenhouse. Once the image is acquired the next step is to implement image processing technique in order to get the information about pest. $[4,5]$

Mono cropped Plantations (coffee) are under constant threat of pest and disease incidence because it favours the build-up of pest population. To cope with these problems, an automatic pest detection algorithm using image processing techniques in MATLAB has been proposed in IOSR Journal of Electronics and Communication Engineering. Image acquisition devices are used to acquire images of plantations at regular intervals. These images are then subjected to pre-processing, transformation and clustering. [3]

\section{PROPOSED SYSTEM}

Borers (Helicoverpa armigera) are insects that attack variety of plants including tomatoes. It enters into tomato plant, stem or fruit by making a small entrance hole which is often difficult to locate. Such affected plants die and has to be uprooted and destroyed. A borer damaged plant that has been given a good care may survive. For this, the tomatoes affected by borer have to be detected at an early stage. This diagnosis is a tedious task to perform manually. Hence detection of biological objects which are very small is a real challenge. With recent advancement in image processing, it is possible to develop a system to identify the initial pest affected tomatoes.

Digital image processing encompasses processes whose inputs and outputs are images and, in addition, encompasses processes that extract attributes from images, up to and including the recognition of individual objects.

The images of tomatoes is captured using a camera and is given as an input to the system. Then the images are processed to interpret the image contents by image processing methods to detect the tomatoes and identify the borer in it. 


\section{METHODOLOGY}

\subsection{Ripeness}

The proposed system first identifies whether the tomato(s) in the given input image is ripe or not. If it is ripe, the system will be terminated, otherwise the input image will be given to the borer-detection algorithm.

\subsection{Color Conversion}

Color conversion is used for the simplicity and data reduction. In this step, the color image is converted to a gray-scale image. Each pixel of the color image contains $\operatorname{red}(\mathrm{R})$, green $(G)$ and blue(B) components which are responsible for the respective color display in the image. These values of $\mathrm{R}$, $\mathrm{G}$ and $\mathrm{B}$ are substituted in a formula to get the value of the of Y [6]. The Y value can be calculated using the formula:

$\boldsymbol{Y}=((\mathbf{0 . 2 9 9}) * \mathrm{R})+((\mathbf{0 . 5 8 7}) * \mathrm{G})+((\mathbf{0 . 1 1 4}) * \mathrm{~B}))$

\subsection{Segmentation}

Segmentation is that process wherein a digital image is partitioned into segments of desired interest. Segmentation is carried out to differentiate the pixels of the area of interest from the rest of the picture. In our project, threshold value of $\mathrm{Y}, \mathrm{Cb}$ and $\mathrm{Cr}$ will be calculated and if the pixel values are within the range, it will be made white; otherwise, it will be made black. $\mathrm{Cb}$ and $\mathrm{Cr}$ values can be calculated using the formulae $[7,8]$ :

$$
\begin{aligned}
& \mathbf{C}_{\mathbf{b}}=(0.564) *(\mathrm{~B}-\mathrm{Y}) \\
& \mathbf{C}_{\mathbf{r}}=(0.713) *(\mathrm{R}-\mathrm{Y})
\end{aligned}
$$

\subsection{Morphology}

After the image has been segmented, there might be chances that the pixels which represent the area-of -interest might be present in areas where it is not desired. For instance, the area of interest here is tomato and this is represented in black color and the background as white. There might be traces of black pixels where the tomato is not present at all. To get rid of these extra black pixels, which can be called noise, morphology is conducted.

Morphology is the process that is carried out to get rid of the noise in the segmented image using the erosion and dilation techniques. The eight-neighbour method is used in this project to perform morphology. The erosion process shrinks the area of interest by comparing the neighbour pixels around the tomato and converts it to the background segment pixel. The dilation process dilates the area of interest (tomato) by comparing the neighbouring pixels of the shrunken tomato and converting it to the pixel used to represent the tomato.

\subsection{Feature Extraction}

It is the method of obtaining the desire object only. In our project we first extract the tomatoes (object of interest). After extracting the tomatoes, our object of interest will be borer which will be extracted (if any) and hence borer will be detected. Experimental Results shown in Fig1 and Fig2.

\subsection{Borer Count}

The system also finds the number of borers present in the affected tomatoes. It also tells the amount of pesticides to be put depending on the number of borers.

\section{EXPERIMENTS AND RESULTS}

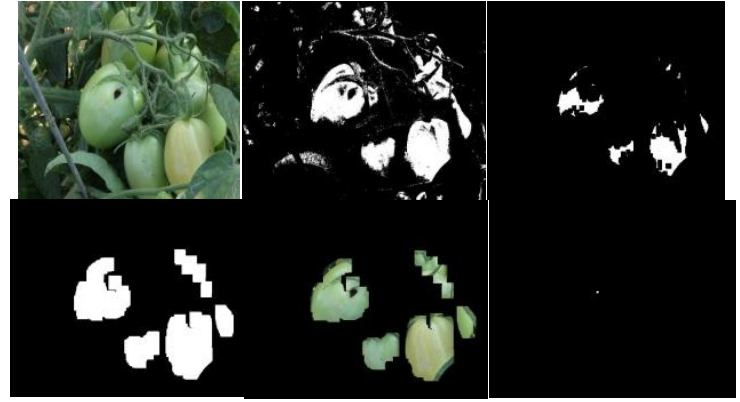

Fig1: Various stages of Borer Extraction for Unzoomed image

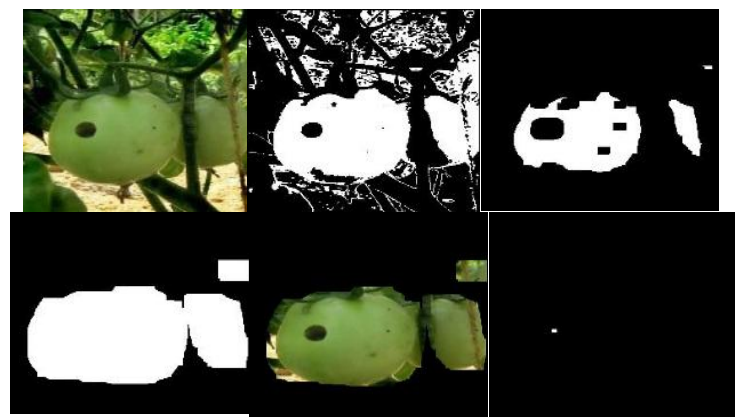

Fig 2: Various stages of Borer Extraction for zoomed image

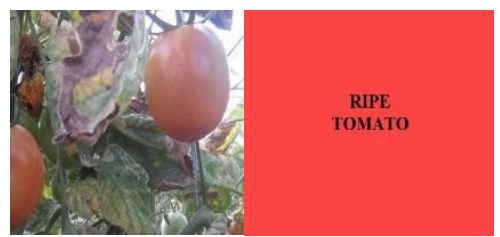

Fig3: Ripe Tomatoes

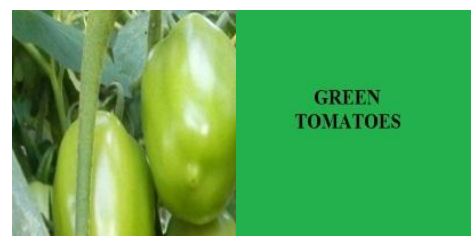

Fig4: Unripe Tomatoes

\section{CONCLUSIONS}

The proposed system here is an efficient and simple algorithm to detect the pests in tomato fruit in the early stage. Since the pests are identified at an early stage, the system also helps in less use of pesticides.

\section{REFERENCES}

[1] Huddar, S.R.; Gowri, S.; Keerthana, K.; Vasanthi, S.; Rupanagudi, S.R., "Novel algorithm for segmentation and automatic identification of pests on plants using image processing," Computing Communication \& Networking Technologies (ICCCNT), 2012 Third International Conference on, vol., no., pp.1,5, 26-28 July 2012

[2] Paul Boissard, Vincent Martin, Sabine Moisan , “A Cognitive Vision Approach to Early Pest Detection in Greenhouse Crops", Computers and Electronics in 
Agriculture 62, 2 (2008) 81-93, DOI : 10.1016/j.compag.2007.11.009

"Pest Control in

[3] Murali Krishnan, Jabert. G Agricultural Plantations Using Image Processing", IOSR Journal of Electronics and Communication Engineering e-ISSN: 2278-2834, p- ISSN: 2278-8735.Volume 6, Issue 4, PP 68-74 , 2013

[4] Rupesh G. Mundada, Dr. V. V. Gohokar, M. E. (Digital Electronics) second year Electronics \& TeleCommunication Department, Shri Sant Gajanan Maharaj College of Engineering, Shegaon, Professor, Electronics \& Tele-Communication Department, Shri Sant Gajanan Maharaj College of Engineering, Shegaon, "Detection and Classification of Pests in Greenhouse Using Image Processing," IOSR Journal of Electronics and Communication Engineering (IOSR-JECE) e-ISSN: 2278-2834,p- ISSN: 2278-8735.Volume 5, Issue 6 (Mar. - Apr. 2013), PP 57-63 www.iosrjournals.org

[5] Ganesh Bhadane, Sapana Sharma, Vijay B. Nerkar, "Early Pest Identification in Agricultural Crops using Image Processing Techniques", International Journal of
Electrical, Electronics and Computer Engineering,7782(2013), ISSN No. (Online): 2277-2626, 2013

[6] Ravoor, P.C.; Ranjani, B.S.; Rupanagudi, S.R., "Optimized fingertip blob recognition for image processing based touch-screens," Recent Advances in Computing and Software Systems (RACSS), 2012 International Conference on, vol., no., pp.104,108, 25 27 April 2012

[7] N. Dhruva, R. R. Sudhir and H. N. Neelkant Kashyap, "Novel Algorithm for Image Processing based Hand Gesture Recognition and its Application in Security," Third International Conference on Advances in Computing, Communication, and Control (ICAC3), Communications in Computer and Information Science, Volume 361, pp. 537 - 547, January 18-19, 2013

[8] Dhruva, N.; Rupanagudi, S.R.; Sachin, S.K.; Sthuthi, B.; Pavithra, R.; Raghavendra, "Novel segmentation algorithm for hand gesture recognition," Automation, Computing, Communication, Control and Compressed Sensing (iMac4s), 2013 International Multi-Conference on , vol., no., pp.383,388, 22-23 March 2013. 